\title{
Comparison between Endobronchial Forceps-Biopsy and Cryo-Biopsy by Flexible Bronchoscopy in the Diagnosis of Lung Cancer
}

\author{
M.A.Moghazy ${ }^{1}$, A.G.Elgazzar ${ }^{1}$, O.I.Mohammad ${ }^{1}$, N.A.Mohammed ${ }^{2}$ and H.H.Moussa ${ }^{1}$ \\ ${ }^{1}$ Chest Diseases, Dept., Faculty of Medicine, Benha Univ., Benha, Egypt \\ ${ }^{2}$ Chest Diseases, Dept., Faculty of Medicine, Kafr Elshiekh Univ., Kafr Elshiekh, Egypt \\ E-mail: Rmdgldya@gmail.com
}

\section{ABSTRACT}

Background: The diagnostic bronchioscopic interventions primary objective is to evaluate and sample tissue of endobronchial lesions, bronchial, pulmonary, hilar-mediastinal lesions or parenchymal lesions utilising various tools that may be introduced through the FB working channel. Target of the work: Our research is aimed at comparing the effectiveness and diagnostic performance of endobronchial cryobiopsies with forceps biopsies in lung cancer detection. Methods and patients: A total of 60 patients have been enrolled. These individuals have been diagnosed with bronchoscopy owing to suspected lung cancer in order to get final diagnosis tissue samples. All operations were performed utilising local lidocaine 2 percent instillation and Midazolam under IV sedation, without endotracheal intubation. Results: This group comprised a total of 60 individuals with suspected endobronchial lesions. Population figures: 16 female (26.7\%) and 44 male (73.3\%) with an average age of $63.40 \pm 9.77$. (16) nonsmokers (36) and (8) ex-smokers were found. All procedures were performed under IV Midazolam and local anaesthetic instillation. The diagnostic results of the cryobiopsy samples were significantly larger than those of forceps ( $\mathrm{p}$ value: 0.005 ). The ultimate diagnosis of forceps biopsy was found in 60 individuals (100\%) compared to $46(76.7 \%)$ with cryobiopsy. Small cell carcinoma was the most frequent diagnosis. Conclusion: Cryobiopsy is a safe and efficient technique for obtaining large tissue samples with better diagnostic efficiency than conventional forceps biopsy.

Keywords: Endobronchial Forceps-Biopsy, Cryo-Biopsy, Flexible Bronchoscopy, Lung Cancer.

\section{Introduction}

Lung cancer is the main cause of cancer mortality worldwide because it is initially asymptomatic and usually found in late stages. [9].

There are current diagnostic and stage recommendations. [8].

Invasive techniques such as bronchoscopic biopsy are frequently utilised in lung cancer diagnosis. The mean diagnostic rate in central malignancies using bronchoscopic forceps biopsy is $74 \%[10]$.

A forceps-biopsy is done to collect tissue with the use of a flexible bronchoscope from patients with endobronchial cancer. A cryo-biopsy recently was also utilised to get tissue samples [2].

In the instance of endobronchial malignancies, the samples with a preserved architecture were found to be bigger using cryoprobes than those with standard forceps to be diagnosed. This led to consideration of the use of cryoprobes for endobronchial biopsy [4].

\section{Aim of the Work}

This study aims to compare the efficacy and diagnostic yield of endobronchial cryobiopsy with forceps biopsy in the diagnosis of lung cancer.

\section{Patients And Methods}

This is a forward-looking, randomised research. The objective of our research was to evaluate the effectiveness and diagnostic performance of endobronchial cryobiopsy with forceps biopsy for lung cancer detection.

\subsection{Patients}

A total of 60 patients have been enrolled. These individuals have been diagnosed with bronchoscopy owing to suspected lung cancer in order to get final diagnosis tissue samples.

The research was authorised by the relevant Committee on Ethics. All patients received written informed permission for bronchoscopy and tissue samples utilising both forceps and cryoprobes.

Bronchoscopy units of the Chest Medicine Department At Benha and Kafr-Elshiekh university hospitals were used for patients suspected of endobronchial lesions.

\subsection{Inclusion criteria}

1-Any patient with central lung mass in chest CT.

2-Normal coagulation profile.

3-PO2 of at least $60 \mathrm{mmHg}$ on room air.

\subsection{Exclusion criteria}

1-Patients unfit for bronchoscopy e.g severe uncorrected hypoxemia despite the administration of supplemental oxygen, unstable angina, uncontrolled arrhythmias, severe hypercarbia and unstable cervical spine

2-Uncorrectable coagulopathy.

3-Acute exacerbation of chronic obstructive pulmonary diseases.

4-Debility, advanced age and malnutrition.

5-Patient refused bronchoscopy.

All patients in the study were subjected to:

- Demographic data of the patients were recorded including: age, sex and smoking state.

- Medical history and clinical examination. 
- Routine laboratory investigations including: complete blood count, serum creatinine, liver enzymes, INR.

- Radiological work up: chest X-ray, chest computed tomography.

- Arterial blood gas on room air.

Statistical Analysis

Data were collected, revised, coded and entered to the Statistical Package for Social Science (IBM
SPSS) version 23. The quantitative data with parametric distribution were presented as mean, standard deviations and ranges. Also qualitative variables were presented as number and percentages. The p-value was considered significant as the following: P-value $>0.05$ : Non significant (NS), Pvalue < 0.05: Significant $(\mathrm{S}), \mathrm{P}$-value < 0.01: Highly significant (HS).

\section{Results}

Table (1) Baseline characteristics demographic data in study group. (N: 60)

\begin{tabular}{llc}
\hline Baseline characteristics & & Total no. $=60$ \\
\hline \multirow{2}{*}{ Age (years) } & Mean \pm SD & $63.40 \pm 9.77$ \\
& Range & $47-88$ \\
Sex & Female & $16(26.7 \%)$ \\
\multirow{2}{*}{ Weight } & Male & $44(73.3 \%)$ \\
& Mean \pm SD & $80.53 \pm 8.97$ \\
Height & Range & $65-96$ \\
& Mean \pm SD & $176.20 \pm 9.65$ \\
Smoking & Range & $159-192$ \\
& Non smoker & $16(26.7 \%)$ \\
& Smoker & $36(60.0 \%)$ \\
\hline
\end{tabular}

This table shows demographic data of study group: the mean \pm SD of age (years) $63.40 \pm 9.77$, they were 16 females $(26.7 \%)$ and 44 males $(73.3 \%)$, weight $(\mathrm{kg}) 80.53 \pm 8.97$, Height $(\mathrm{cm}) 176.20 \pm 9.65$, they were (16) non smokers (36) smokers and (8) ex-smokers of baseline characteristics.

Table (2) Comparison between forceps and cryo results.

\begin{tabular}{|c|c|c|c|c|c|}
\hline & $\begin{array}{l}\text { Forceps } \\
\text { No. }=60\end{array}$ & $\begin{array}{c}\text { Cryo } \\
\text { No. }=60\end{array}$ & Test value & P-value & Sig. \\
\hline Small cell lung cancer & $16(26.7 \%)$ & $18(30.0 \%)$ & $0.082 *$ & 0.774 & $\mathrm{NS}$ \\
\hline Squamous cell carcinoma & $10(16.7 \%)$ & $14(23.3 \%)$ & $0.417 *$ & 0.518 & NS \\
\hline Benign inflammatory polyp ${ }^{* *}$ & $8(13.3 \%)$ & $0(0.0 \%)$ & $4.286^{*}$ & 0.038 & S \\
\hline Adenocarcinoma & $8(13.3 \%)$ & $10(16.7 \%)$ & $0.131 *$ & 0.717 & NS \\
\hline Carcinoid tumor & $4(6.7 \%)$ & $6(10.0 \%)$ & $0.218^{*}$ & 0.641 & NS \\
\hline Spindle cell carcinoma & $4(6.7 \%)$ & $4(6.7 \%)$ & $0.000 *$ & 1.000 & NS \\
\hline Papillary carcinoma & $2(3.3 \%)$ & $4(6.7 \%)$ & $0.351 *$ & 0.554 & NS \\
\hline Polymorphic carcinoma & $2(3.3 \%)$ & $4(6.7 \%)$ & $0.351 *$ & 0.554 & NS \\
\hline Chronic inflammatory lesion** & $2(3.3 \%)$ & $0(0.0 \%)$ & $1.017 *$ & 0.313 & NS \\
\hline chronic bronchitis $* *$ & $2(3.3 \%)$ & $0(0.0 \%)$ & $1.017^{*}$ & 0.313 & NS \\
\hline Non conclusive for malignancy** & $2(3.3 \%)$ & $0(0.0 \%)$ & $1.017 *$ & 0.313 & NS \\
\hline
\end{tabular}

P-value > 0.05: Non significant; P-value < 0.05: Significant; P-value < 0.01: Highly significant

The previous table shows that there was no statistically significant difference found between forceps and cryo regarding the results of the studied patients. The cases which diagnosed by cryo and not diagnosed by forceps were found to be either Benign inflammatory polyp (8)cases, Chronic inflammatory lesion(2)case, Chronic bronchitis(2)case or Non conclusive for malignancy (2)case.

Table (3) Comparison between forceps and cryo regarding diagnostic yield.

\begin{tabular}{llllll}
\hline & Forceps & Cryo & Test value & P-value & Sig. \\
No. $=60$ & $\begin{array}{l}\text { No. }=60 \\
60(100.0 \%)\end{array}$ & 7.925 & 0.005 & HS \\
Diagnostic & $\begin{array}{l}46.7 \%) \\
\text { Not diagnostic }\end{array}$ & $14(23.3 \%)$ & $0(0.0 \%)$ & & \\
\hline
\end{tabular}

The previous table shows that there was statistically significant higher incidence of non diagnostic patients in forceps results $(23.3 \%)$ than cryo results $(0.0 \%)$ with $\mathrm{p}$-value $=0.005$. 


\section{Discussion}

Forceps biopsy is the conventional method for bronchoscopic visual lesions diagnosis [6].

Many variables may impact on the diagnostic result of the procedure including: diameter, location, pathological nature and tumour visibility, and the size and quality of the sample collected [5].

The diagnostic performance of the conventional forceps biopsy may be enhanced by using additional instruments such as brushings, pulleys and washes. However, the total cost, time and potential problems of the procedure including anaesthesia will be increased [6].

The purpose of this research is to evaluate the effectiveness and diagnostic output of endobronchial cryobiopsy with the diagnosis of lung cancer. forceps biopsy.

The present research included 60 instances 16 $(27 \%)$ were girls and $44(73 \%)$ were men with endobronchial visible lesions. In the same patient six forceps biopsies were performed compared with four cryobiopsies. Their age varied from 47 to 88 years, their average weight was 65 to $96 \mathrm{~kg}$ with a height of 159 to $192 \mathrm{~cm}$, they were non-smoking smokers (36) and ex smoking smokers [8].

In all patients of the study group, symptoms were present as follows: ( 30) cases of dyspnea, (12) cases of hemoptysis, (10) cases of chest pain, and (8) cases of persistent cough whereas in $46(73.3 \%)$ cases, in 6 $(10.0 \%)$ cases, CT was found mass, in $8(13.3 \%)$ cases, in $6(10.0 \%)$ consolidation and collapse.

Despite the lower number of cryobiopsies than forceps biopsies in our research, the diagnostic output of cryobiopsia was considerably greater than forceps biopsies (60 patients (100 percent) were cryobiopsis and 46 (76.7 percent) forceps).).

In 600 patients with suspected endobronchial lesions Hetzel et al. [7] evaluated the diagnostic output of the cryobiopsy against the conventional forceps biopsy. The ultimate number of patients covered was 593. Patients were randomised for either forceps or cryoprobe samples. The cryobiopsy diagnostic output was considerably greater than the biopsy forceps. The final diagnosis in conventional forceps biopsy was obtained in $85.1 \%$ and in cryobiopsy in $95.0 \%$. (P value 0.001 ).

Aktas et al. [1] showed that the diagnostic yield of cribobiopsy is greater than forceps biopsy. In 41 patients with endobronchial lesions, both cryobiopsia and forceps biopsia were examined. Both procedures were performed with three forceps biopsies and one cryobiopsy in each subject. In 38 individuals (92.7\%) the definitive diagnosis was achieved in the cryobiopsy vs $32(78 \%)$ in the forceps biopsy.

Schumann et al. [7] evaluated a total of 296 endoluminal tumour patients. The final patients comprised 55 individuals; the same patient was treated with both cryobiopsies and forceps biopsies. Cryobiopsy showed a substantially better diagnostic yield than forceps biopsy (89.1 percent vs 65.5 percent, $\mathrm{P}<0.05$ ).

Although the patient in our research is somewhat limited, it can demonstrate the superiority and safety of the cryobiopsy method and provide supporting information to the increasing experience of endobronchial cryobiopsy.

With regard to the histological analysis of the samples, small cell lung cancer was the most frequent tumour identified in this research. Three uncommon kinds of lung cancers based on cryobiopsy and forceps have been identified. The first was polymorphic carcinoma, the second was papillary carcinoma, and the third was spindle cell tumour all samples collected from both forceps and cryobiopsies were diagnosed.

\section{Conclusion}

Cryobiopsy is a safe and efficient technique for obtaining bigger tissue samples with more diagnostic output compared to conventional biopsy forceps.

\section{References}

[1] Z.Aktas, E.Gunay, NT.Hoca, A.Yilmaz, F.Demirag, S.Gunay . Endobronchial cryobiopsy or forceps biopsy for lung cancer diagnosis. Ann Thorac Med.vol.5,pp.242246,2010.

[2] H.Eldeeb and S.Reza Northampton outcome for first and second line chemotherapy in nonsmall cell lung cancer: 5 years data. Contemporary Oncology.vol.16,pp.420450,2012.

[3] J.Hetzel, R.Eberhardt, FJ.Herth, C.Petermann, G.Reichle, L.Freitag. Cryobiopsy increases the diagnostic yield of endobronchial biopsy: a multicentre trial. Eur Respir.vol.39,pp.685690,2012.

[4] J.Hetzel, M.Hetzel, C.Hasel, P.Moeller and A.Babiak Old Meets Modern: The Use of Traditional Cryoprobes in the Age of Molecular Biology. Respiration.vol.76,pp.193-197,2008.

[5] K.Roth, JA.Hardie, AH.Andreassen, F.Leh, TML.Eagan Predictors of diagnostic yield in bronchoscopy: a retrospective cohort study comparing different combinations of sampling techniques. BMC Pulmonary medicine.vol.8,pp.144-147,2008.

[6] ER.Rubio, SR.le, RE.Whatley, MB.Boyd Cryobiopsy: Should This Be Used in Place of Endobronchial Forceps Biopsies?. Biomed Res Int.vol.133,pp.200-233,2013.

[7] C.Schumann, J.Hetzel, AJ.Babiak, T.Merk, T.Wibmer, P.Möller.Cryoprobe biopsy increases the diagnostic yield in endobronchial tumor lesions. J Thorac Cardiovasc Surg.vol.140,pp 417- 421,2010. 
[8] RL.Siegel, KD.Miller, A.Jemal Cancer statistics CA Cancer J Clin.vol.68,pp.730,2018.

[9] 9-World Health Organization (WHO) Lung cancer. Available at:http://globocan.iarc.fr/ Pages/fact_sheets_cancer.aspx.Accessed August.vol.11,pp.52-58,2018.

[10] A.Zafer, G.Ersin, T.Nevin, Y.Aydin, D.Funda, G.Sibel. Endobronchial cryobiopsy or forceps biopsy for lung cancer diagnosis, Ann. Thorac. Med.vol.5,pp. 242-246,2010. 